\title{
Exploring nanocrystalline cellulose as a green alternative of carbon black in natural rubber/butadiene rubber/styrene-butadiene rubber blends
}

\author{
W. J. Chen, J. Gu*, S. H. Xu \\ College of Materials Science and Engineering, South China University of Technology, 510640 Guangzhou, China
}

Received 2 January 2014; accepted in revised form 2 May 2014

\begin{abstract}
A series of nanocrystalline cellulose (NCC) reinforced natural rubber/butadiene rubber/styrene-butadiene rubber (NR/BR/SBR) blends were prepared via mastication of NR/NCC, BR/SBR and other ingredients. Resorcinol and hexamethylene tetramine (RH) was adopted to modify the interface between NCC and rubber matrix. The morphology, dynamic viscoelastic behavior, apparent crosslink density, mechanical performance and dynamic mechanical property of $\mathrm{NR} / \mathrm{BR} / \mathrm{SBR} / \mathrm{NCC}$ blends were discussed in detail. The results showed that NCC was uniformly dispersed in composites and RH could enhance the adhesion of NCC and matrix. According to the dynamic mechanical analysis, NCC performed comparable reinforcing effect with carbon black (CB), and the modulus was improved with modification of RH. Mechanical tests showed that the replacement of CB by NCC in the blends did not deteriorate mechanical properties of composites. Besides, the blends exhibited best mechanical properties, when 10 phr NCC substituted CB.
\end{abstract}

Keywords: nanocomposites, nanocrystalline cellulose, $N R / B R / S B R$, reinforcements

\section{Introduction}

Carbon black is one of the most commonly used reinforcing fillers in rubber for its excellent reinforcement in combination with low cost. However, in the mixing process, $\mathrm{CB}$ has such defect as environmental pollution, energy consumption and time consumption. Additionally, CB is charged with consuming the depleting petroleum resources for its manufacture and more or less contributes to the accumulation of greenhouse gases. Considering the limited resource and the environmental burden, it is a meaningful topic to reduce the petroleum dependency of industrial products. Thus, many researchers tend to investigate various kinds of bio-based renewable materials as the alternatives of $\mathrm{CB}$ in rubber.

Cellulose, one of the most abundant biorenewable materials, has its advantages as a reinforcing filler in rubber: low cost, low density, low energy consumption; high specific strength and modulus; easy processability, reactive surface, easy recycling and degradable property $[1,2]$. Actually, not few lectures have reported the application of cellulose in rubber. Since Favier and co-workers [3] firstly reinforced rubber latex with nano-scale cellulose, lots of researches have managed to extract cellulose from nature, namely, rattan [4], bagasse [5], cassava [6], kenaf [7], sisal [8], oil palm [9] etc., and to apply as the reinforcing agent in rubber. Results show that cellulose reinforces the rubber latex effectively. Besides, cellulose could bring additional benefits when serving as the filler in rubber, such as relatively easy-degradable property of rubber composites [10], reduced Payne effect of filler [11], improved abrasion resistance [12] and so on. Therefore, cellulose is the promising reinforcing filler of rubbers.

\footnotetext{
${ }^{*}$ Corresponding author, e-mail: psjgu@scut.edu.cn

(C) BME-PT
} 
The influences of fillers' properties on rubber composites mainly depend on the size, shape and surface properties; among them, the size distribution is the most important factor [13]. The smaller the size, the better the reinforcing effect. And the surface properties determine the compatibility and interaction of filler-rubber. Besides, the dispersion of fillers is also the premise of excellent reinforcing effect. It was reported that nanoscale cellulose could reinforce not only polar rubber latex $[14,15]$ but also apolar rubber latex [6]. For apolar matrix, modification of cellulose/matrix interaction would do a great favor to the properties $[9,16]$. There were also literatures making comparisons of reinforcing effect between cellulose and commercial fillers, most of which showed negative results after replacing commercial fillers by cellulose, due to the difference of polarity and bad interaction $[4,12,17]$.

The development of various rubber products and the requirement of elastomer with special behaviors motivate the development of rubber blends. Compounding two or more kinds of rubber with certain ratios usually contributes to the integration of behaviors, in spite of synergistic effect in some aspects. Until now, a great part of elastomer products consist of rubber blends, such as tyres, conveyors, tubes and so on. While, it is relatively uncommon in the literatures to study the rubber blends reinforced by cellulose.

In this paper, the masterbatch technique was adopted to fill NR/BR/SBR with NCC, which might be also acceptable for other rubber blends. The coagulation method was the approach used to get NR/NCC masterbatches, which was clean and simple to carry out and could ensure good dispersion of NCC in rubber. Then, the resulting masterbatches were used to mixing and reinforcing BR and SBR. In order to improve the interaction between rubber and cellulose, resorcinol and RH was added to modify the $\mathrm{NCC} /$ matrix interface, which was widely used as an coupling agent to improve the rubber-filler interaction $[9,18,19]$. Lastly, the structure, morphology and performance of NCC loaded NR/BR/SBR blends were investigated by scanning electron microscopy (SEM), rubber process analysis (RPA), apparent crosslink density, dynamic mechanical analysis (DMA) and mechanical properties tests.

\section{Experimental}

\subsection{Materials}

Microcrystalline cellulose (MCC, industrial grade) was provided by the Gaoli Chemical Company in Guangzhou, China. The sulfuric acid (95 98 wt\%) of analytical grade was the product of Chemical R\&D Center in Guangdong province, China. To get the NCC, sulfuric acid with a concentration of $64 \mathrm{wt} \%$ had been prepared and used to hydrolyze microcrystalline cellulose for $30 \mathrm{~min}$ at $45^{\circ} \mathrm{C}$. After the acid hydrolysis process, NCC solution was washed repeatedly by distilled water until $\mathrm{pH}$ reached $6 \sim 8$, via centrifugation.

Natural rubber latex (61 wt $\%$ ) was purchased from Eleventh Rubber Factory of Guangzhou, China. Anhydrous calcium chloride (analytical grade) was produced by Tianjin Fuchen Chemical Company, China. BR9000 and SBR1500 were supplied by Guangzhou Rubber Industrial Product Research Institute Co., Ltd. N330 grade carbon black (nitrogen absorption surface area $78 \mathrm{~m}^{2} / \mathrm{g}$ ) was obtained from China Rubber Company (produced in Anshan). RH was the product of Guoli Chemical Industry and Technology in China. The molecule structure of RH was showed in Figure 1. Other rubber compounding ingredients were all of industrial grade.

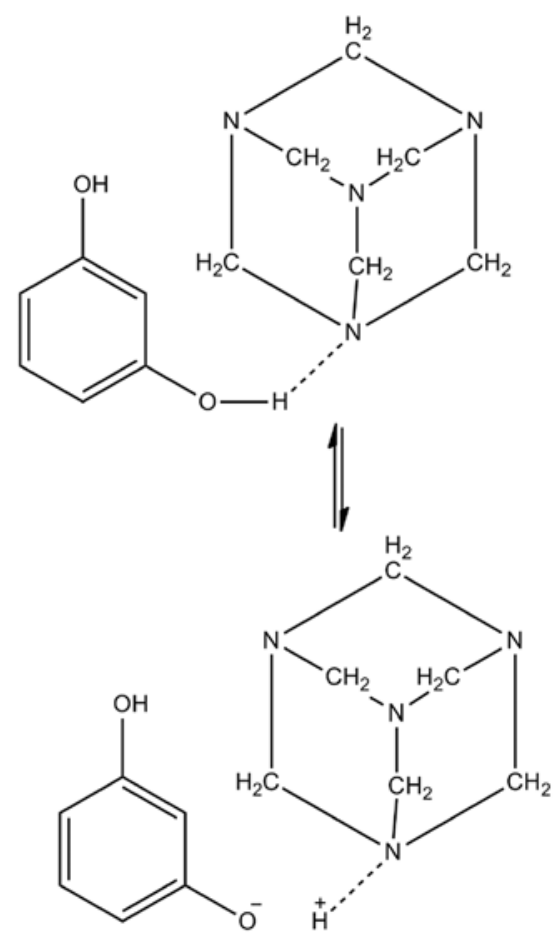

Figure 1. Molecular structure of RH 


\subsection{Preparation of $\mathrm{NR} / \mathrm{BR} / \mathrm{SBR} / \mathrm{NCC}$ composites}

With certain NR/NCC ratios $(60 / 0,60 / 5,60 / 10$, $60 / 15,60 / 20$ ), NCC suspension and NR latex were mixed by intense mechanical stirring in order to get a homogeneous mixture, followed by the coagulation step with the help of $\mathrm{CaCl}_{2}$ solution. Then, the coagulated NR/NCC compound was washed with clean water for enough time to remove impurity. After that, the obtained NCC/NR materbatch was dried in a ventilated oven at $70^{\circ} \mathrm{C}$ until constant weight.

NCC and CB loaded rubber compounds were prepared in a two-roll mill (according to ASTM D3182-07), based on the formulation in Table 1. Mastication process of NCC/NR masterbatch, BR and SBR had to be continued about 3 minutes. Then certain amount of CB fillers $(45,40,35,30,25 \mathrm{phr})$ were added to reach the total fillers volume of $45 \mathrm{phr}$, along with other ingredients, including the modifier RH. The nip-gap, mill roll, speed ratio and the number of passes were kept the same for all samples. The milling step was concluded by passing the compounds four times through the mill at a setting of $6 \mathrm{~mm}$, taking care to maintain the direction of compounds and to ensure the orientation along the flow direction to some degree. The last step was followed by vulcanization, which was carried out at $150^{\circ} \mathrm{C}$ for a corresponding cure time $\left(T_{90}\right)$ with a hot press, to obtain composite sheets with a $1 \mathrm{~mm}$ thickness. Additionally, the other ingredients of composites were fixed as: zinc oxide $5 \mathrm{phr}$, stearic acid $2 \mathrm{phr}$, CZ $1.5 \mathrm{phr}$, accelerator DM $0.5 \mathrm{phr}$, antiaging agent 4010NA $1.5 \mathrm{phr}$, sulfur $1.5 \mathrm{phr}$.

Table 1. Compounding formulation [phr]

\begin{tabular}{|c|c|c|c|c|c|}
\hline $\begin{array}{c}\text { Sample } \\
\text { codes }\end{array}$ & NR/NCC & BR & SBR & $\begin{array}{c}\text { CB } \\
\text { (N330) }\end{array}$ & RH \\
\hline $0 / 45 / 0$ & \multirow{2}{*}{$60 / 0$} & \multirow{2}{*}{20} & \multirow{2}{*}{20} & \multirow{2}{*}{45} & 0 \\
\hline $0 / 45 / 4$ & & & & & 4 \\
\hline $5 / 40 / 0$ & \multirow{2}{*}{$60 / 5$} & \multirow{2}{*}{20} & \multirow{2}{*}{20} & \multirow{2}{*}{40} & 0 \\
\hline $5 / 40 / 4$ & & & & & 4 \\
\hline $10 / 35 / 0$ & \multirow{2}{*}{$60 / 10$} & \multirow{2}{*}{20} & \multirow{2}{*}{20} & \multirow{2}{*}{35} & 0 \\
\hline $10 / 35 / 4$ & & & & & 4 \\
\hline $15 / 30 / 0$ & \multirow{2}{*}{$60 / 15$} & \multirow{2}{*}{20} & \multirow{2}{*}{20} & \multirow{2}{*}{30} & 0 \\
\hline $15 / 30 / 4$ & & & & & 4 \\
\hline $20 / 25 / 0$ & \multirow{2}{*}{$60 / 20$} & \multirow{2}{*}{20} & \multirow{2}{*}{20} & \multirow{2}{*}{25} & 0 \\
\hline $20 / 25 / 4$ & & & & & 4 \\
\hline
\end{tabular}

\subsection{Characterization}

Micrographs of NCC and vulcanizates were obtained with a field emission scanning electron microscope
(Nova NanoSEM 430, FEI Company, Netherlands). A copper grid was used to salvage NCC from diluted NCC suspension. Then the NCC and fractured surfaces of various composites were sputter-coated with gold prior to taking pictures.

X-ray diffraction (XRD) tests were carried out using an X'Pert Pro MRD (PANalytical B. V.). The diffraction patterns were recorded using $\mathrm{Cu}-\mathrm{K} \alpha$ radiation at $40 \mathrm{kV}$. Crystallinity was calculated by the following Equation (1) [20]:

Crystallinity $=1-\frac{I_{\mathrm{am}}}{I_{002}}$

where $I_{002}$ is the maximum intensity of the peak at $2 \theta$ around $23^{\circ}$ and $I_{\text {am }}$ is the minimum intensity of the peak at $2 \theta$ around $18^{\circ}$.

Microstructure analysis of MCC and NCC was conducted by Fourier transform infrared spectroscopy (Migna 760, the Nicolet Company), after mixing it with spectroscopy grade potassium bromide $(\mathrm{KBr})$ powder.

The experiments of strain sweeps were carried out by RPA2000 (Alpha technologies, US), under the following test configuration: preheat the samples at $60^{\circ} \mathrm{C}$ inside the cavity for 2 min with $0.1 \%$ strain and $1 \mathrm{~Hz}$ frequency, so as to get a stable temperature and release built-in stress of samples; then strain sweeping was done between 0.2 to $150 \%$ strain at $60^{\circ} \mathrm{C}$ and a frequency of $1 \mathrm{~Hz}$.

Prediction of cured samples' apparent crosslink density $\left(V_{\mathrm{r}}\right)$ was done according to equilibrium swelling experiments, as reported in [21].

Dumbbell specimens (6 mm width in cross-section, $1 \mathrm{~mm}$ thickness) and un-nicked $90^{\circ}$ angle test pieces (1 mm thickness) were prepared for the stress-strain (ASTM D412) and tear strength (ASTM D624) test respectively, via tensile strength tester (UT-2060, UCAN Dynatex Inc., Taiwan) with a crosshead speed of $500 \mathrm{~mm} / \mathrm{min}$. Shore A hardness was determined under the conditions given in ASTM-D2240. The dynamic mechanical behaviors of composites were measured by a dynamic mechanical analyzer (DMA242C NETZSCH; Germany) in tension mode (static force $0.5 \mathrm{~N}$, dynamic force $5.0 \mathrm{~N}$, force factor 1.1, amplitude $80.0 \mu \mathrm{m}$,). Samples were prepared with a size of $8 \mathrm{~mm}$ length, $1 \mathrm{~mm}$ thickness and $6 \mathrm{~mm}$ width. The scan temperature was run from 100 to $100^{\circ} \mathrm{C}$ with a heating ramp of $3{ }^{\circ} \mathrm{C} / \mathrm{min}$ and a frequency of $10 \mathrm{~Hz}$. 


\section{Results and discussion}

\subsection{Characterization of cellulose}

NCC, prepared by acid hydrolysis of MCC, was analyzed via SEM as shown in Figure 2. The SEM image revealed the existence of isolated rod-like cellulose with diameters ranging from 20 to $140 \mathrm{~nm}$ and lengths below $2 \mu \mathrm{m}$. This rod-like nano-cellulose would become potentially excellent reinforcing filler [13].

According to the XRD pattern displayed in Figure 3, MCC and NCC had similar XRD curves. Both MCC and NCC had peaks at $2 \theta$ angles 15, 16.7, 22.9, $34.7^{\circ}$, which was attributed to the reflections from $11^{\prime} 0$ and 110, 020 and 004 lattice planes, respectively; and the $2 \theta$ angles 15, 16.7, 22.9 implied a crystalline structure of cellulose I [10, 22]. Besides, the crystallinity of MCC and NCC were calculated to be 87.12 and $87.96 \%$, respectively, which were almost the same. Thus, the acid hydrolysis hardly

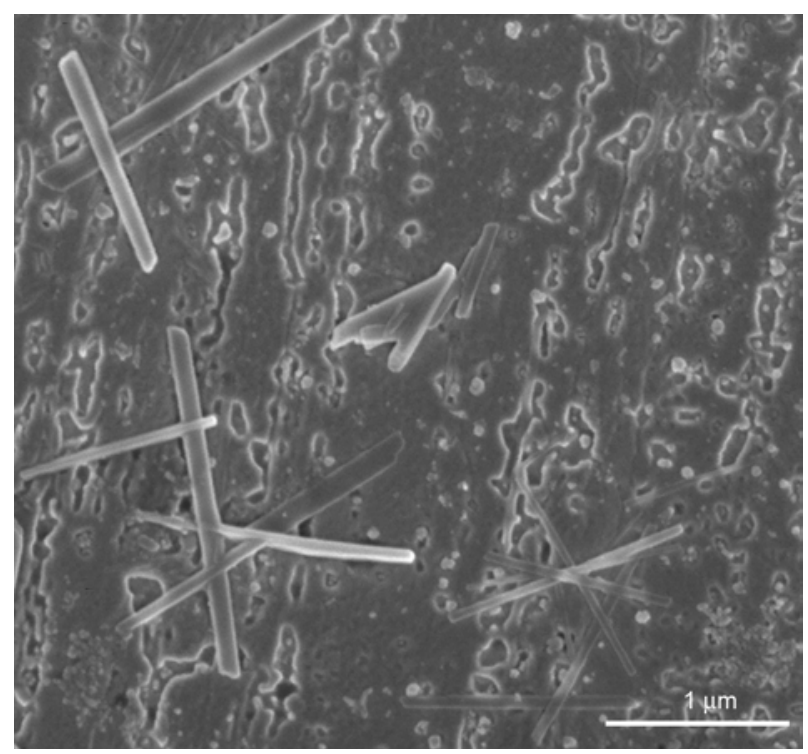

Figure 2. SEM image of NCC

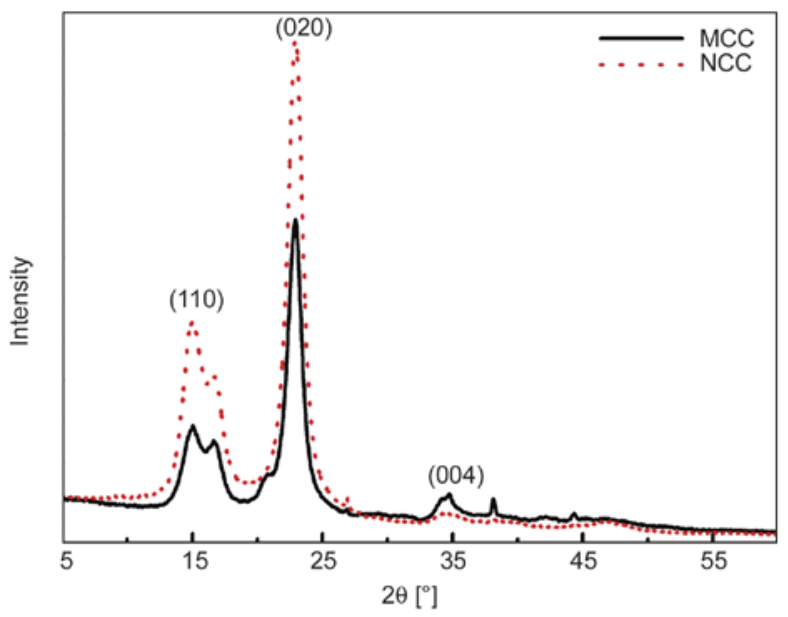

Figure 3. XRD spectrum of MCC and NCC

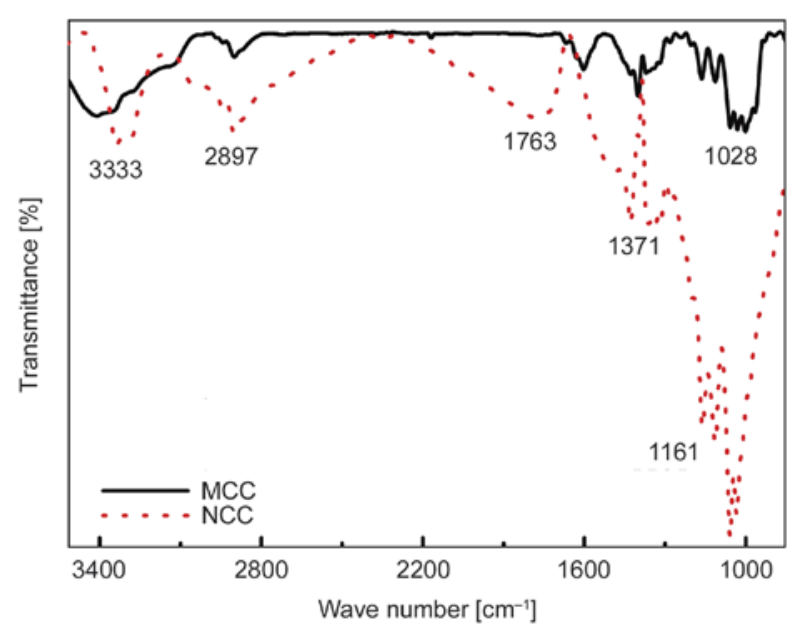

Figure 4. FTIR spectrum of MCC and NCC

reduced crystallinity. A slightly difference maybe the shapes of peaks at 38.1 and $44.3^{\circ}$ : all the peaks of NCC above $25^{\circ}$ tended to extensively broaden and were not easy to figure out. The explanation was that the acid hydrolysis mainly took place at amorphous regions and imperfect crystalline regions. Hence, the peaks of NCC at large-angle tended to fade away and those at small-angle, however, were sharpened. The retention of crystalline area could retain the mechanical property of cellulose, which led to a good reinforcing effect.

Fourier transform infrared (FTIR) spectrum of MCC powder and NCC suspension was exhibited in Figure 4. The broad peak from 3400 to $3300 \mathrm{~cm}^{-1}$ indicated $\mathrm{OH}$ groups in cellulose. Transmittance at $2897 \mathrm{~cm}^{-1}$ belonged to alkyl CH stretches. Absorption peak at $1317,1338,1371 \mathrm{~cm}^{-1}$ corresponded to $\mathrm{CH}_{2}$ rocking vibrations, $\mathrm{OH}$ bending vibrations and $\mathrm{CH}$ bending vibrations, respectively. The peak at $1429 \mathrm{~cm}^{-1}$ belonged to $\mathrm{CH}_{2}$ bending. And 1161, $1112,1057,1031 \mathrm{~cm}^{-1}$ were characteristics of cellulose $\mathrm{I}^{\prime} \mathrm{C}-\mathrm{O}-\mathrm{C}-\mathrm{O}-\mathrm{C}$ bond [23]. According to the mentioned peaks, the acid hydrolysis process did not cause chemical changes in cellulose. However, there was a new peak at $1760 \mathrm{~cm}^{-1}$ of NCC, which probably denoted the carbonyl group of lactones at the chain end. Explanation maybe that the degradation of cellulose increased chain ends, thus resulting in the appearance of $\mathrm{C}=\mathrm{O}$ peak.

\subsection{Morphology analysis of NR/BR/SBR composites}

The tensile fracture surfaces of rubber composites filled with various $\mathrm{NCC} / \mathrm{CB} / \mathrm{RH}$ ratios were displayed in Figure 5. The fillers, both NCC and CB, 


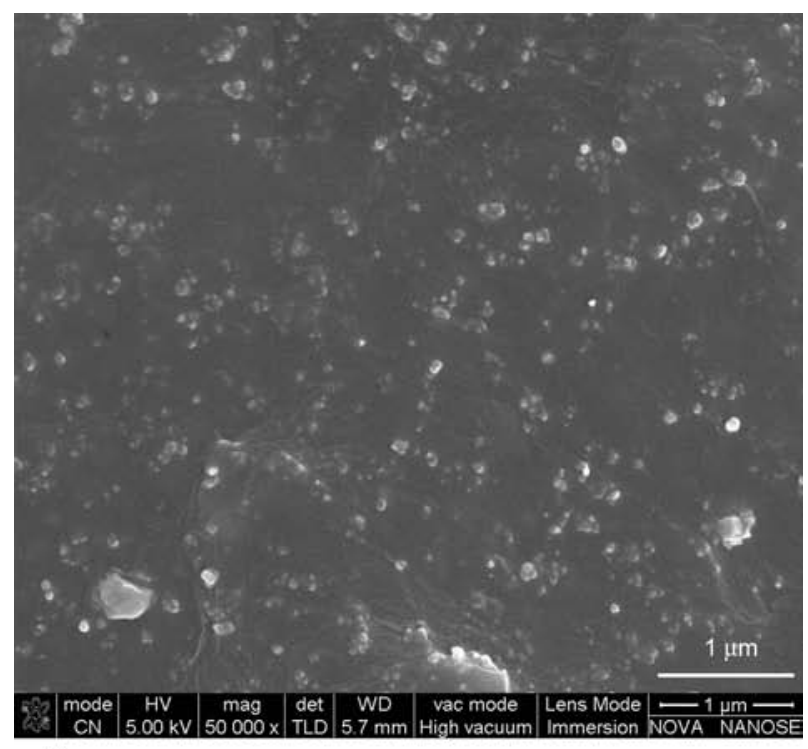

a)

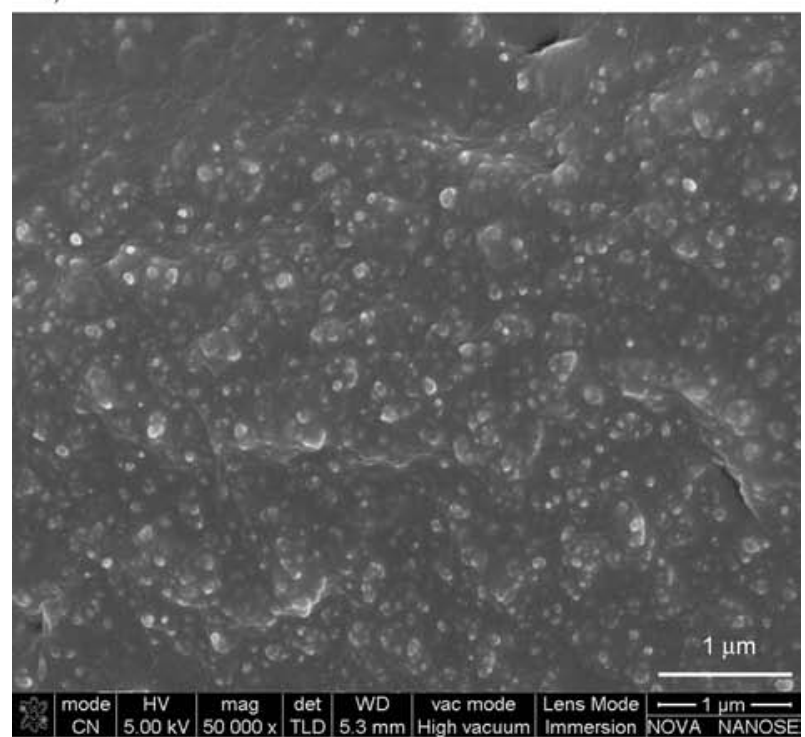

b)

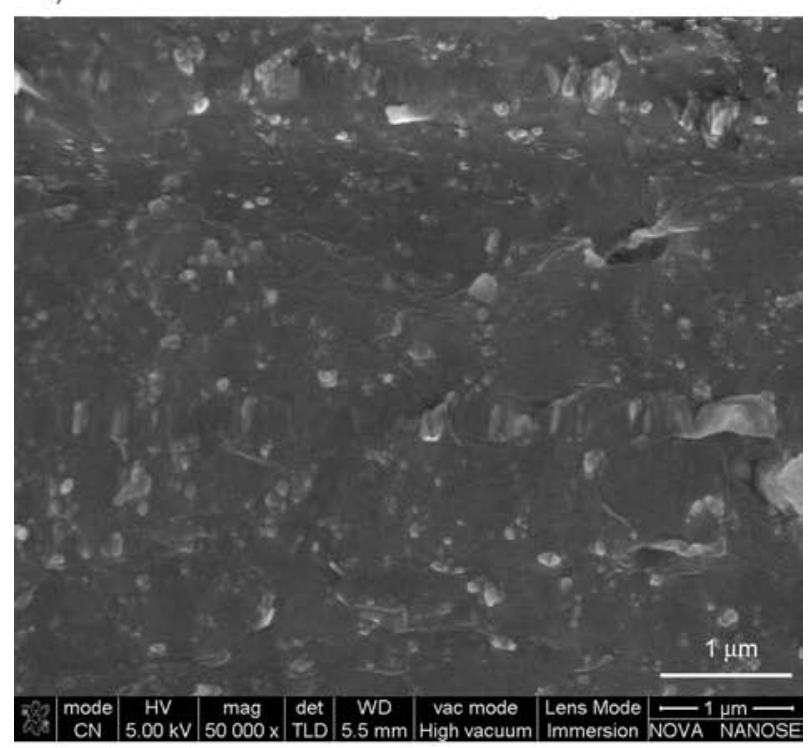

c)

Figure 5. SEM images of NR/BR/SBR composites reinforced by NCC and CB: (a) NCC/CB/RH 0/45/0; (b) $\mathrm{NCC} / \mathrm{CB} / \mathrm{RH} 10 / 35 / 0$; (c) NCC/CB/RH 10/35/4 in the rubber matrix could easily be identified as white dots. The micrographs of various vulcanizates revealed a relatively uniform morphology of the surface and displayed a slightly rolling section, which indicated good distribution of fillers and ductile fracture of composites, respectively. Besides, it's hard to find rod-like filler in NCC-loaded composites (Figure $5 \mathrm{~b}$ and $5 \mathrm{c}$ ), suggesting NCC oriented in the stretching direction. Because the orientation effect might be caused while the tensile fracture surfaces were prepared. It showed that the white dots in Figure $5 b$ were relatively more and bigger than those in Figure 5a. Because the adhesion between NCC and matrix was poor, the fracture tended to happen along the interface of NCC/rubber, hence more exposure of NCC. Incorporation of RH helped to improve compatibility and adhesion, so boundary of NCC and matrix in Figure $5 \mathrm{c}$ tended to be obscure. That microstructure of composites would affect the mechanical properties, discussed in last parts.

In order to study the distribution of NCC in rubber, composites with only NCC filler were prepared and showed in Figure 6. The images illustrated the fracture surfaces of RH modified composite (Figure 6b) and without RH modification (Figure 6a). Several holes were observed in unmodified composite (Figure 6a), since some of the NCC was pulled out from the matrix. However, the surfaces of modified ones were smoother: most of the NCC was totally embedded in matrix, only showing up as dots. This indicated a strong interaction between NCC and rubber matrix, due to the modification of $\mathrm{RH}$.

\subsection{RPA 2000 analysis of $N R / B R / S B R$ compounds}

RPA was carried out to identify the network condition of uncured compounds, displayed in Figure 7. The total modulus reflecting both stable and unstable (major part) network could described by storage modulus $\left(G^{\prime}\right)$ in small strain [24]. The unstable network commonly indicated the filler network and showed as the Payne effect [25]. Figure 7 illustrated that $G^{\prime}$ decreased as NCC partly displaced CB. This was because $\mathrm{CB}$ could form bound rubber [26], thus performing high modulus. Nevertheless, NCC networks were relatively weaker than those of $\mathrm{CB}$. The substitution of $\mathrm{CB}$ by NCC diluted the $\mathrm{CB}$ network [27] and facilitated good dispersion of fillers. However, an unusual phenomenon was that the very low amount (4 phr) of RH involved in the compound led 


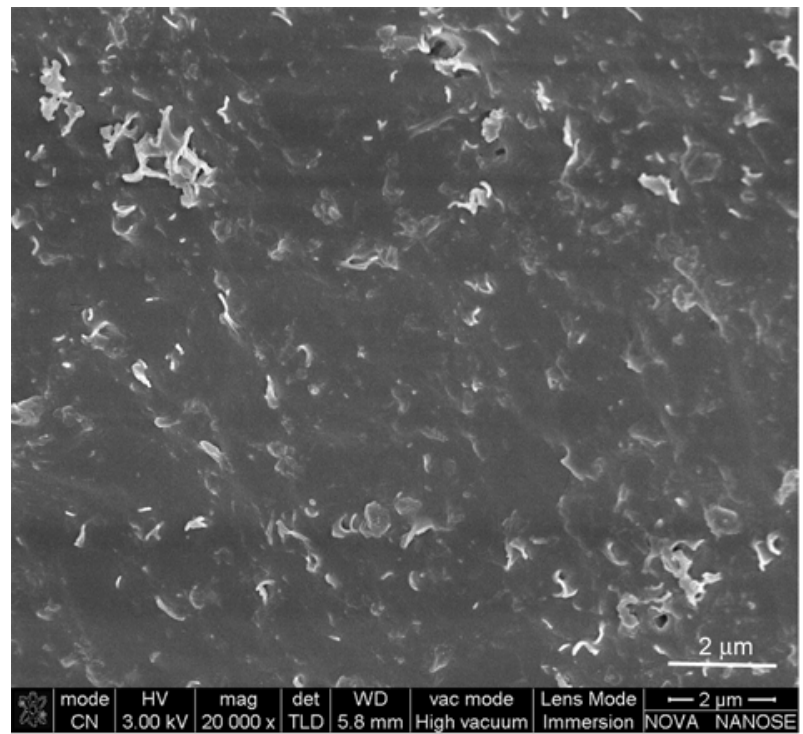

a)

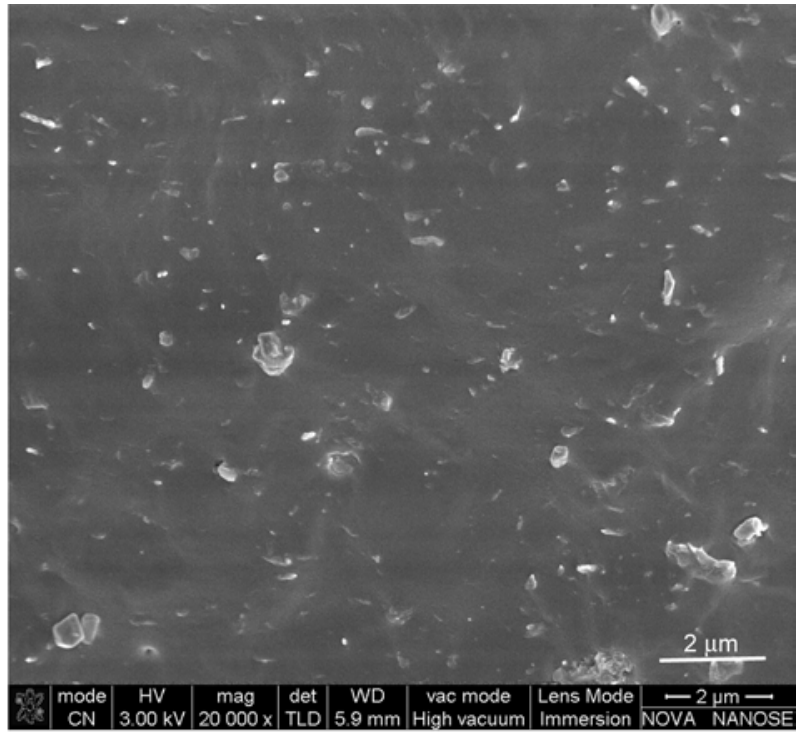

b)

Figure 6. SEM images of NR/BR/SBR composites filled with NCC: (a) NCC/CB/RH 10/0/0; (b) NCC/CB/RH 10/0/4
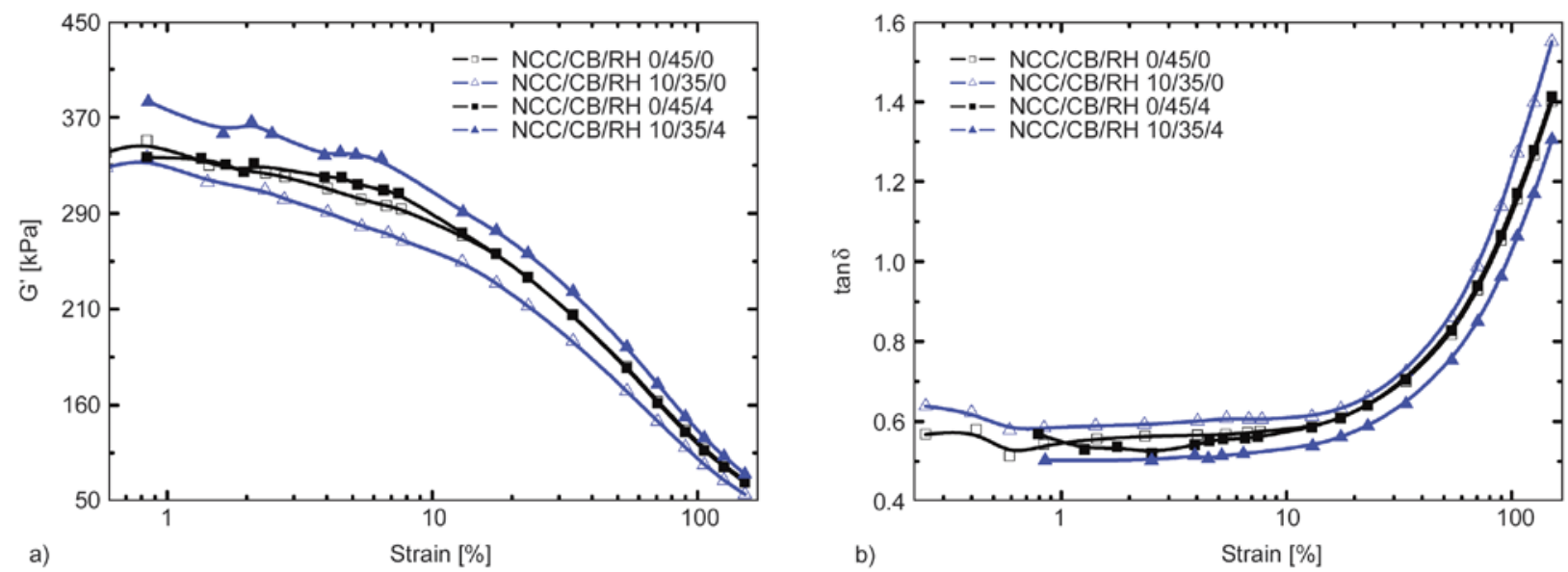

Figure 7. $G^{\prime}$-strain (a) and $\tan \delta$-strain (b) curves of uncured NR/BR/SBR compounds

to an obvious rise in the modulus. It's worth noting that RH has not developed chemical link with rubber in the uncured compounds. So this rise was mainly attributed to the physical interaction of $\mathrm{RH}$ with filler. The hydrogen bond of RH/NCC has been verified in our previous publications [28]. It could be deduced that, with the existence of $\mathrm{RH}$, NCC network seemed to be enhanced by hydrogen bond via RH. The fact that the addition of RH hardly affected the modulus of control samples (compounds without NCC) further proved it: this part of increase only resulted from the interaction of NCC/RH.

The loss tangent $(\tan \delta)$ is the ratio of dissipated energies and storage energies in every cyclic strain. According to Wang [29], the breakdown and reformation of the network would result in an additional energy dissipation during cyclic strain, which was evaluated by hysteresis $(\tan \delta)$. Figure 7 showed a rise in $\tan \delta$ as NCC partly replace $\mathrm{CB}$, for polar and rod-like $\mathrm{NCC}$ caused more friction than $\mathrm{CB}$ among macromolecules. However, the $\tan \delta$ was lower than in the control sample for RH modified compounds, since hydrogen bond enhanced the NCC network.

\subsection{Apparent crosslink densities of NR/BR/SBR composites}

Apparent crosslink densities of rubber/ $\mathrm{NCC} / \mathrm{CB}$ composites were displayed in Figure 8. It showed that, without the modification of $\mathrm{RH}$, the substitution of NCC for CB led to a gradual decline in $V_{\mathrm{r}}$, especially when fillers ratios reached $20 / 25$. The abundant hydroxyl group in NCC could interact with curing agents, resulting in the decline of $V_{\mathrm{r}}$ [30]. After modified by RH, composites showed markedly improved but irregularly varying $V_{\mathrm{r}}$ as a function of 


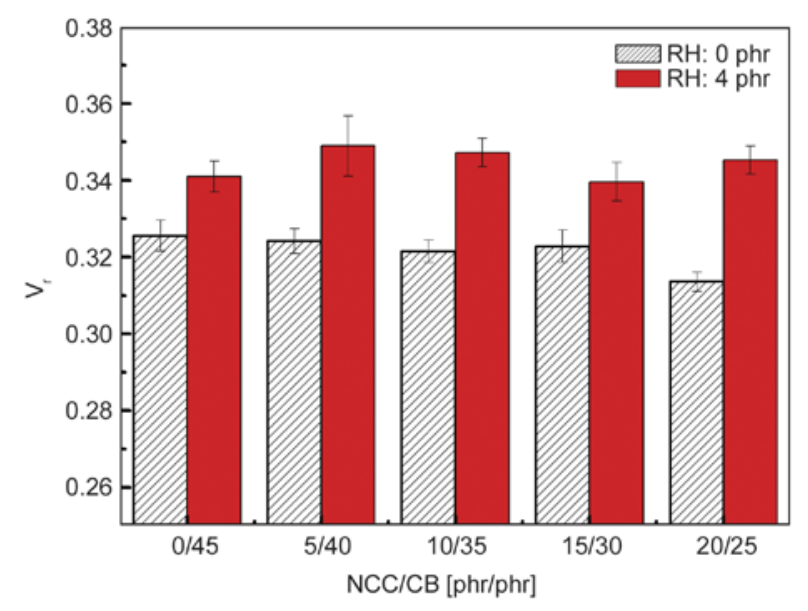

Figure 8. Apparent crosslink densities of NR/BR/SBR composites reinforced by $\mathrm{NCC}$ and $\mathrm{CB}$

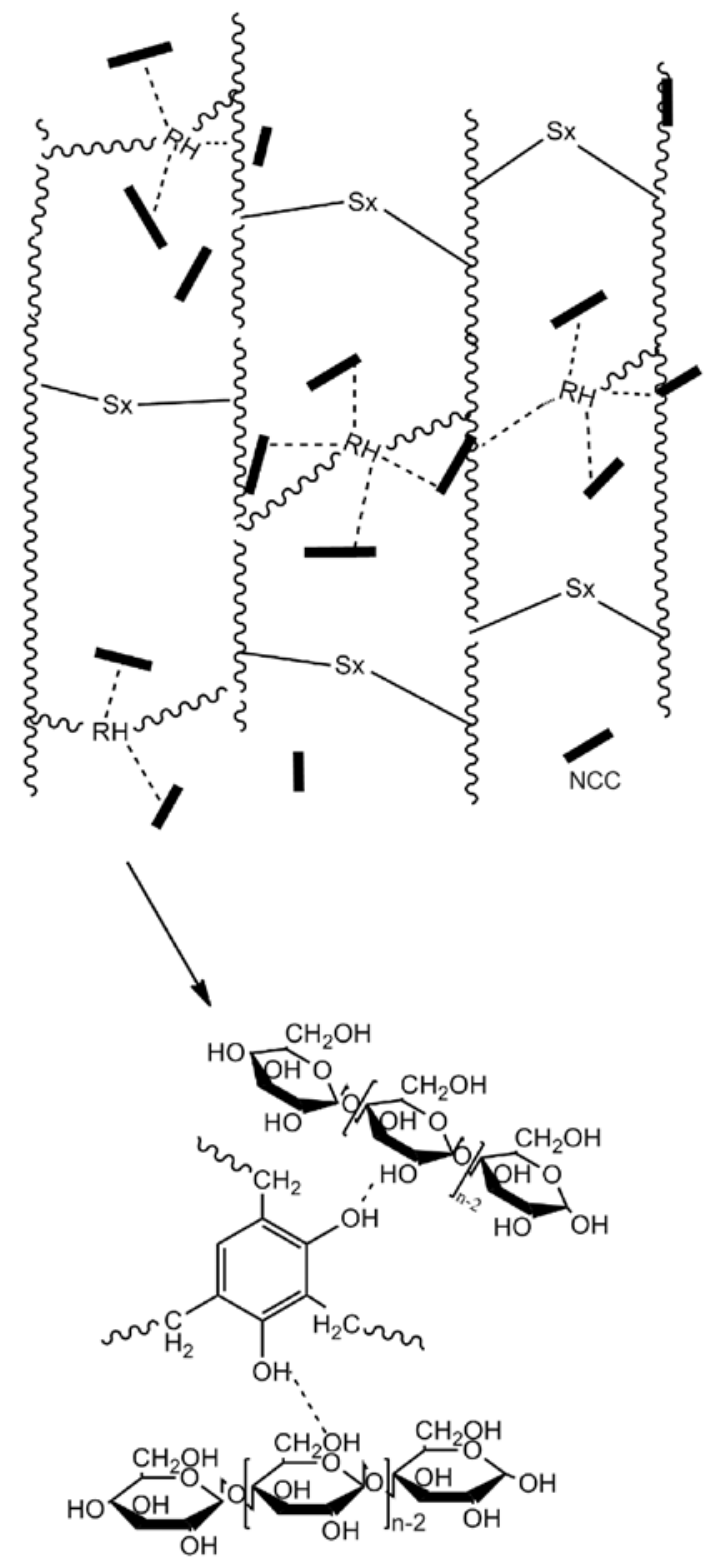

Figure 9. Interaction between NCC and macromolecules in modified composites [32] fillers ratios. It was because at the cure temperature, RH would decompose into phenols, methyl and amine, which reacted in situ with the macromolecules to form resorcinol-formaldehyde resin [31]. Through it, active sites to polar fillers were introduced in the low-polarity rubber molecules as shown in Figure 9 [32]. Besides, amine generally facilitated the curing process $[33,34]$. Therefore, the apparent crosslink densities were improved by $\mathrm{RH}$. On the other hand, the existence of RH also influenced the NCC network as reflected in the RPA data, hence elevating $V_{\mathrm{r}}$ and preserving $V_{\mathrm{r}}$ as fillers ratio changed.

\subsection{Dynamic mechanical performance of NR/BR/SBR composites}

DMA was conducted to explore the dynamic response of $\mathrm{CB}$ and NCC loaded composites. The curves of storage modulus $\left(E^{\prime}\right)$ and $\tan \delta$ and corresponding characteristics were shown in Figure 10 and Table 2, respectively. There were obvious reductions of $E^{\prime}$ at the temperature ranging from -80 to $-45^{\circ} \mathrm{C}$, followed by a rubbery plateau. And the $\tan \delta$ reached the top peak at about $-55^{\circ} \mathrm{C}$, illustrating the glass transition $\left(T_{\mathrm{g}}\right)$ of composites. Comparison of different samples showed that the replacement of CB by NCC did not impair the reinforcing effect, which was reflected by the slightly increased

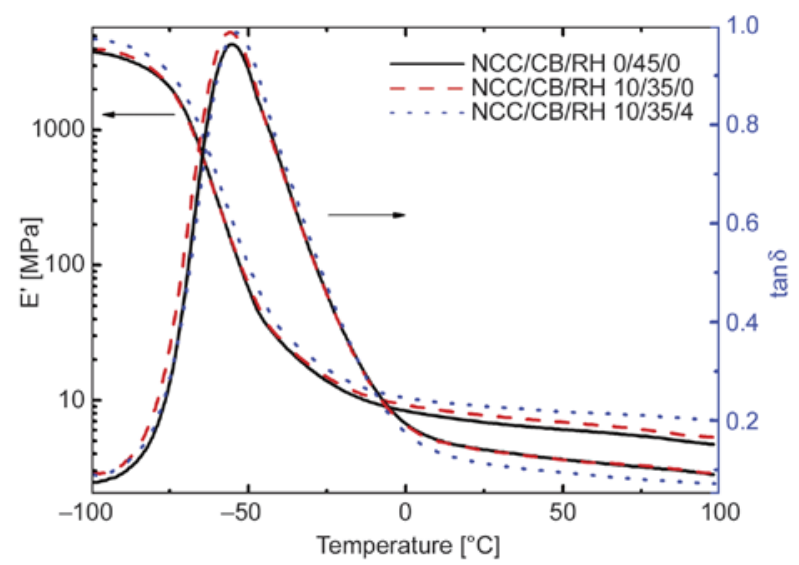

Figure 10. $E^{\prime}-T$ and $\tan \delta-T$ curves of NR/BR/SBR composites reinforced by $\mathrm{NCC}$ and $\mathrm{CB}$

Table 2. Data of the $E^{\prime}$ and $\tan \delta-T$ curves of NCC-loaded NR/BR/SBR composites

\begin{tabular}{|l|c|c|c|c|}
\hline $\mathbf{N C C} / \mathbf{C B} / \mathbf{R H}$ & $\begin{array}{c}\mathbf{T}_{\mathbf{g}} \\
{\left[{ }^{\circ} \mathbf{C}\right]}\end{array}$ & $\begin{array}{c}\mathbf{E}^{\prime}{ }_{\left(25^{\circ} \mathbf{C}\right)} \\
{[\mathbf{M P a}]}\end{array}$ & $\tan \boldsymbol{\delta}_{\left(\mathbf{0}^{\circ} \mathbf{C}\right)}$ & $\tan \boldsymbol{\delta}_{\left(60^{\circ} \mathbf{C}\right)}$ \\
\hline $0 / 45 / 0$ & -55.2 & 6.867 & 0.1942 & 0.1151 \\
\hline $10 / 35 / 0$ & -55.8 & 7.751 & 0.1906 & 0.1144 \\
\hline $10 / 35 / 4$ & -53.9 & 9.023 & 0.1761 & 0.0887 \\
\hline
\end{tabular}


value of $E^{\prime}$. And modification of RH further facilitated this tendency. The reinforcement of NCC was due to the high aspect ratio and modulus [35]. So, a certain amount of NCC could perform comparable reinforcing effect with $\mathrm{CB}$. Additionally, RH enhanced the NCC network by hydrogen bonding and linked this network to rubber molecules, as shown in the previous part. Besides, the contribution of RH to rubber crosslink also played a role.

The loss tangent $(\tan \delta)$ is the ratio of dissipated energies and storage energies. It is the value to characterize internal friction. The higher the $\tan \delta$, the more friction the internal system suffers and the more heat is produced in the system. According to the characteristics of $\tan \delta, \tan \delta$ at the temperature above $0^{\circ} \mathrm{C}$ decreased slightly upon the replacement of CB by NCC. The existence of RH also decreased the $\tan \delta$, because $\mathrm{RH}$ facilitated the crosslinking of

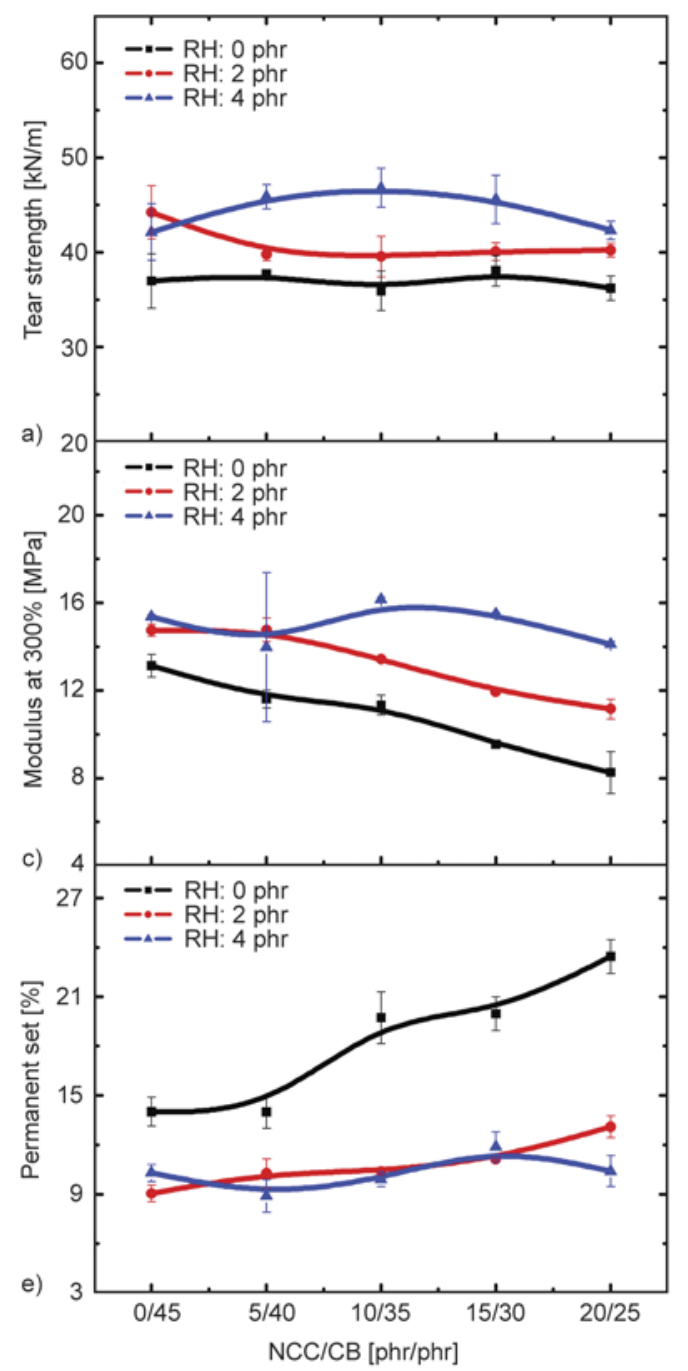

rubber. This trend suggested a low rolling resistance and probably reduced heat built-up.

\subsection{Mechanical properties of $N R / B R / S B R$ composites}

The mechanical properties of NCC and CB loaded composites were exhibited in Figure 11. It showed that the substitution of CB by NCC did not cause obvious deterioration of the mechanical properties. And the elongation at break was even improved from 400 to $500 \%$, after $20 \mathrm{phr}$ NCC replacing CB. These comparable performances of NCC loaded composites with CB-filled ones were possibly due to the nano-effect [13] of cellulose and good dispersion of fillers, supported by SEM images. If need to mention some defects, it were permanent set and modulus at $300 \%$ that were undermined. This tendency was a result of weak adhesion of polar NCC

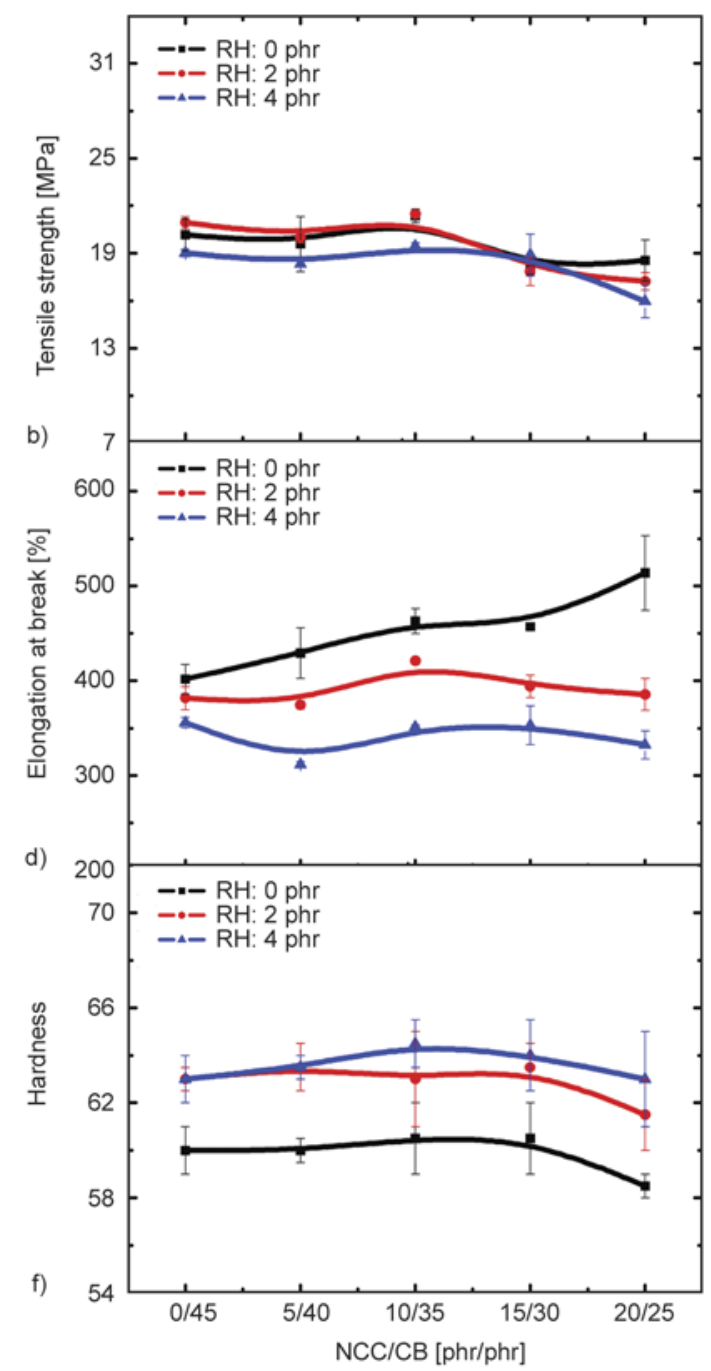

Figure 11. Mechanical properties of NR/BR/SBR composites reinforced by NCC and CB, (a) tear strength; (b) tensile strength; (c) modulus at 300\%; (d) elongation at break; (e) permanent set; (f) hardness 
and nonpolar rubber matrix. The incorporation of RH eliminated those defects: permanent set was obviously decreased, so did the increasing rate as a function of NCC content; modulus at $300 \%$ was enhanced and the tendency did not always decline as NCC increased. Tear strength and hardness were also markedly improved by RH. Among various fillers ratios, 10/35 was the optimal one to obtain the best mechanical properties, which may be a result of the good synergistic reinforcement of the two kinds of filler network.

\section{Conclusions}

Acid hydrolysis was adopted to obtain NCC, which was a kind of nanomaterial and possessed perfect crystal structure. Then, resulting NCC had been used to reinforce NR/BR/SBR blends as the substitute of CB. SEM images revealed good dispersion of NCC in blends. The RH strengthened the interaction of NCC and matrix. DMA revealed comparable reinforcement of NCC with CB. Mechanical properties showed samples with a high NCC loading of $10 \mathrm{phr}$ performed best behaviors, indicating good reinforcing effect of NCC. The incorporation of RH would further improve the mechanical properties. In summary, NCC partially replacing $\mathrm{CB}$, through stated method, led to well performance of NR/BR/SBR blends according to investigated aspects, along with environmental benefits and economic interests.

\section{Acknowledgements}

This work was financially supported by the National Science Foundation of China (No. 51173046) and National Science Foundation of China - Joint Fund of Guangdong Province (No. U1134005).

\section{References}

[1] Azizi Samir M. A. S., Alloin F., Dufresne A.: Review of recent research into cellulosic whiskers, their properties and their application in nanocomposite field. Biomacromolecules, 6, 612-626 (2005).

DOI: $10.1021 / \mathrm{bm} 0493685$

[2] Siró I., Plackett D.: Microfibrillated cellulose and new nanocomposite materials: A review. Cellulose, 17, 459-494 (2010). DOI: $10.1007 / \mathrm{s} 10570-010-9405-\mathrm{y}$

[3] Favier V., Chanzy H., Cavaille J. Y.: Polymer nanocomposites reinforced by cellulose whiskers. Macromolecules, 28, 6365-6367 (1995).

DOI: $10.1021 / \mathrm{ma} 00122 \mathrm{a} 053$
[4] Muniandy K., Ismail H., Othman N.: Effects of partial replacement of rattan powder by commercial fillers on the properties of natural rubber composites. Bioresources, 7, 4640-4657 (2012).

[5] Kanking S., Niltui P., Wimolmala E., Sombatsompop N.: Use of bagasse fiber ash as secondary filler in silica or carbon black filled natural rubber compound. Materials and Design, 41, 74-82 (2012).

DOI: $10.1016 /$ j.matdes.2012.04.042

[6] Pasquini D., Teixeira E. M., Curvelo A. A. S., Belgacem M. N., Dufresne A.: Extraction of cellulose whiskers from cassava bagasse and their applications as reinforcing agent in natural rubber. Industrial Crops and Products, 32, 486-490 (2010).

DOI: $10.1016 /$ j.indcrop.2010.06.022

[7] Wang D., Shang S-B., Song Z-Q., Lee M-K.: Evaluation of microcrystalline cellulose prepared from kenaf fibers. Journal of Industrial and Engineering Chemistry, 16, 152-156 (2010).

DOI: $10.1016 /$ j.jiec.2010.01.003

[8] Martins M. A., Forato L. A., Mattoso L. H. C., Colnago L. A.: A solid state ${ }^{13} \mathrm{C}$ high resolution NMR study of raw and chemically treated sisal fibers. Carbohydrate Polymers, 64, 127-133 (2006).

DOI: $10.1016 /$ j.carbpol.2005.10.034

[9] Jacob M., Thomas S., Varughese K. T.: Mechanical properties of sisal/oil palm hybrid fiber reinforced natural rubber composites. Composites Science and Technology, 64, 955-965 (2004).

DOI: 10.1016/S0266-3538(03)00261-6

[10] Bras J., Hassan M. L., Bruzesse C., Hassan E. A., ElWakil N. A., Dufresne A.: Mechanical, barrier, and biodegradability properties of bagasse cellulose whiskers reinforced natural rubber nanocomposites. Industrial Crops and Products, 32, 627-633 (2010). DOI: $10.1016 /$ j.indcrop.2010.07.018

[11] Xu S. H., Gu J., Luo Y. F., Jia D. M.: Effects of partial replacement of silica with surface modified nanocrystalline cellulose on properties of natural rubber nanocomposites. Express Polymer Letters, 6, 14-25 (2012). DOI: $10.3144 /$ expresspolymlett.2012.3

[12] Karaağaç B.: Use of ground pistachio shell as alternative filler in natural rubber/styrene-butadiene rubberbased rubber compounds. Polymer Composites, 35, 245-252 (2014). DOI: $10.1002 / p c .22656$

[13] Hamed G. R.: Reinforcement of rubber. Rubber Chemistry and Technology, 73, 524-533 (2000). DOI: $10.5254 / 1.3547603$

[14] Cao X., Xu C., Liu Y., Chen Y.: Preparation and properties of carboxylated styrene-butadiene rubber/cellulose nanocrystals composites. Carbohydrate Polymers, 92, 69-76 (2013).

DOI: $\underline{10.1016 / \mathrm{j} . \mathrm{carbpol} .2012 .09 .054}$ 
[15] Cao X., Xu C., Wang Y., Liu Y., Liu Y., Chen Y.: New nanocomposite materials reinforced with cellulose nanocrystals in nitrile rubber. Polymer Testing, 32, 819-826 (2013). DOI: $10.1016 /$ j.polymertesting.2013.04.005

[16] Ljungberg N. J., Bonini C., Bortolussi F., Boisson C., Heux L., Cavaillé J. Y.: New nanocomposite materials reinforced with cellulose whiskers in atactic polypropylene: Effect of surface and dispersion characteristics. Biomacromolecules, 6, 2732-2739 (2005).

DOI: $10.1021 / \mathrm{bm} 050222 \mathrm{v}$

[17] Bhattacharyya S. K., Parmar B. S., Chakraborty A., Dasgupta S., Mukhopadhyay R., Bandyopadhyay A.: Exploring microcrystalline cellulose (MCC) as a green multifunctional additive (MFA) in a typical solutiongrade styrene butadiene rubber (S-SBR)-based tread compound. Industrial and Engineering Chemistry Research, 51, 10649-10658 (2012).

DOI: $10.1021 / \mathrm{ie} 301268 \mathrm{e}$

[18] Geethamma V. G., Thomas Mathew K., Lakshminarayanan R., Thomas S.: Composite of short coir fibres and natural rubber: Effect of chemical modification, loading and orientation of fibre. Polymer, 39, 14831491 (1998).

DOI: 10.1016/S0032-3861(97)00422-9

[19] Sui G., Zhong W. H., Yang X. P., Yu Y. H.: Curing kinetics and mechanical behavior of natural rubber reinforced with pretreated carbon nanotubes. Materials Science and Engineering: A, 485, 524-531 (2008). DOI: $10.1016 /$ j.msea.2007.09.007

[20] Segal L., Creely J. J., Martin A. E., Conrad C. M.: An empirical method for estimating the degree of crystallinity of native cellulose using the X-ray diffractometer. Textile Research Journal, 29, 786-794 (1959). DOI: $10.1177 / 004051755902901003$

[21] Flory P. J., Rehner Jr J.: Statistical mechanics of cross-linked polymer networks II. Swelling. The Journal of Chemical Physics, 11, 521-626 (1943). DOI: $10.1063 / 1.1723792$

[22] Sassi J-F., Chanzy H.: Ultrastructural aspects of the acetylation of cellulose. Cellulose, 2, 111-127 (1995). DOI: 10.1007/BF00816384

[23] Zhang J., Pan S.: Study on the FTIR of microcrystalline celluloses. Journal of Cellulose Science and Technology, 3, 22-27 (1995).

[24] Payne A. R.: Strainwork dependence of filler-loaded vulcanizates. Journal of Applied Polymer Science, 8, 2661-2686 (1964).

DOI: 10.1002/app.1964.070080614
[25] Payne A. R., Whittaker R. E.: Low strain dynamic properties of filled rubbers. Rubber Chemistry and Technology, 44, 440-478 (1971).

DOI: $10.5254 / 1.3547375$

[26] Dannenberg E. M.: Bound rubber and carbon black reinforcement. Rubber Chemistry and Technology, 59, 512-524 (1986).

DOI: $10.5254 / 1.3538213$

[27] Wang M. J.: Effect of filler-elastomer interaction on tire tread performance Part I: Hysteresis of filled vulcanizates. Kautschuk und Gummi, Kunststoffe, 60, 438-443 (2007).

[28] Xu S., Gu J., Luo Y., Jia D., Yan L.: Influence of nanocrystalline cellulose on structure and properties of natural rubber/silica composites. Polymer Composites, in press (2014). DOI: $10.1002 / p c .23005$

[29] Wang M-J.: Effect of polymer-filler and filler-filler interactions on dynamic properties of filled vulcanizates. Rubber Chemistry and Technology, 71, 520589 (1998).

DOI: $10.5254 / 1.3538492$

[30] Bahl K., Jana S. C.: Surface modification of lignosulfonates for reinforcement of styrene-butadiene rubber compounds. Journal of Applied Polymer Science, 131, 40123/-40123/9 (2014). DOI: $10.1002 / a p p .40123$

[31] Darwish N. A.: Effect of bonding systems on the adhesion of nitrile rubber to nylon cord. Polymer-Plastics Technology and Engineering, 39, 793-806 (2000).

[32] Gu J., Chen W-J., Lin L., Luo Y-F., Jia D-M.: Effect of nanocrystalline cellulose on the curing characteristics and aging resistance properties of carbon black reinforced natural rubber. Chinese Journal of Polymer Science, 31, 1382-1393 (2013).

DOI: $10.1007 / \mathrm{s} 10118-013-1340-6$

[33] Liu Y. B., Li L., Wang Q.: Reinforcement of natural rubber with carbon black/nanoclay hybrid filler. Plastics, Rubber and Composites, 39, 370-376 (2010). DOI: $10.1179 / 174328910 X 12691245469871$

[34] Avalos F., Ortiz J. C., Zitzumbo R., López-Manchando M. A., Verdejo R., Arroyo M.: Effect of montmorillonite intercalant structure on the cure parameters of natural rubber. European Polymer Journal, 44, 31083115 (2008). DOI: 10.1016/j.eurpolymj.2008.07.020

[35] Favier V., Canova G. R., Cavaillé J. Y., Chanzy H., Dufresne A., Gauthier C.: Nanocomposite materials from latex and cellulose whiskers. Polymers for Advanced Technologies, 6, 351-355 (1995). DOI: $10.1002 /$ pat.1995.220060514 